\title{
A “MAIOR FAVELA FLUVIAL DO MUNDO” NOS MATERIAIS DIDÁTICOS DE HISTÓRIA DO AMAPÁ: O ENSINO DA HISTÓRIA LOCAL DO MUNICÍPIO LARANJAL DO JARI (AMAZÔNIA BRASILEIRA)
}

\author{
MARÍlIA PANTOJA dO NASCIMENTO* \\ ANDRIUS ESTEVAM NORONHA**
}

Resumo: o município de Laranjal do Jari, o terceiro maior município do estado do Amapá (IBGE: 2016), localizado cerca de $265 \mathrm{~km}$ da capital, Macapá, frequentemente é estereotipado como "a maior favela fluvial do mundo". Este discurso é reforçado nos principais materiais didáticos destinado ao ensino de História do Amapá publicados nesta última década como Amapá: vivendo nossa história (2008), escrito por Marcelo André Soares e Maria Emília Brito Rodrigues e História do Amapá: o passado é o espeIho do presente (2009), escrito por Paulo Dias Morais. O objetivo deste artigo consiste em problematizar as narrativas referentes formação de Laranjal do Jari nestes materiais didáticos. A partir das problematizações, a relevância deste artigo consiste em contribuir com as reflexões sobre as possibilidades dos usos destes materiais para o ensino de história local.

Palavras-chave: Livro Didático e Paradidático, História Local, Laranjal do Jari.

\section{The "largest flavor favel of the world" in Amapá history materials: the teaching of the local history of the Laranjal do Jari (Brazilian Amazon) municipality}

\begin{abstract}
The municipality of Laranjal do Jari, the third largest municipality in the state of Amapá (IBGE: 2016), located about 265km from the capital, Macapá, is often stereotyped as "the largest river favela in the world". This discourse is reinforced in the main didactic material destined to the teaching of History of Amapá published in the last decade as Amapá: living our history (2008), written by Marcelo André Soares and Maria Emília Brito Rodrigues and History of Amapá: the past is the mirror of the present (2009), written by Paulo Dias Morais. The objective of this article is to problematize the narratives concerning the formation of Laranjal do Jari in these didactic materials. From the problematizations, the relevance of this article is to contribute with the reflections on the possibilities of the uses of these materials for the teaching of local history.

Keywords: Didactic and Paradidatic Book, Local History, Laranjal do Jari.
\end{abstract}

\section{Introdução}

De acordo com a professora e historiadora Circe Bittencourt existe uma forma de distinguir os tão variados materiais didáticos utilizados na mediação do processo de aquisição de conhecimento na atualidade, dividindo-os em duas categorias

\footnotetext{
* Historiadora, Especialista em História da Amazônia, Mestre em Ensino de História pela Universidade Federal do Amapá. Professora de História da rede pública estadual de ensino do Amapá.

** Doutor em História pela Pontifícia Universidade Católica do Rio Grande do Sul (PUCRS). Professor da Universidade Federal do Amapá. Vice-Coordenador do Mestrado Profissional em Ensino de História da Universidade Federal do Amapá.
} 
principais: os suportes informativos e os documentos (Bittencourt, 2011, p. 296).

Os suportes informativos "correspondem a todo discurso produzido com a intenção de comunicar elementos do saber das disciplinas escolares" (Bittencourt, 2011). Alguns exemplos de suportes informativos são: livros didáticos e paradidáticos, apostilas dos sistemas de ensino particulares, atlas escolares, dicionários escolares e determinados produtos como vídeos, CDs, DVDs, etc. Eles fazem parte da indústria cultural e são elaborados previamente com o intuito de serem utilizados em meios educacionais por apresentarem linguagem própria para determinada faixa etária, constituírem saberes mais técnicos e possuírem princípios pedagógicos (Bittencourt, 2011).

Já os documentos são aqueles produzidos em uma perspectiva que não fazem parte originalmente dos saberes das disciplinas escolares, mas que, posteriormente, podem ser utilizados com a finalidade didática. Assim, eles são produzidos para atingirem um público mais amplo e não têm preocupação e intenção didáticas predefinidas. Sua utilização em meios escolares depende da seleção e/ou produção feita por professores ou pela escola. Alguns exemplos de documentos são: contos, lendas, filmes de ficção, textos jornalísticos, documentários, revistas, fotografias, pinturas, cartas, etc. (Bittencourt, 2011, p 296-297)

Para este escrito, consideraremos essencialmente dois tipos de materiais didáticos: os livros didáticos e paradidáticos. Segundo o filósofo Jörn Rüsen (2011, p.109), "todos os especialistas estão de acordo em que o livro didático é a ferramenta mais importante no ensino de história" além disso, "é o segundo gênero de leitura mais lido pelos leitores brasileiros, ficando atrás apenas da Bíblia" (Guimarães: 2012, p. 92). Sua influência dentro do processo de ensino e aprendizagem é inegável, por conta disso, o livro didático tem sido investigado sob diversos ângulos em diversos países.

O pesquisador Alain Choppin afirma que "após ter sido negligenciado, tanto pelos historiadores quanto pelos bibliógrafos, os livros didáticos vêm suscitando um vivo interesse entre os pesquisadores de uns trinta anos para cá" (2004, p. 549) As pesquisas históricas acerca dos manuais e edições escolares apresentam múltiplas possibilidades de abordagens, e Choppin destaca duas categorias principais de análise: a primeira refere-se às pesquisas que concebem o livro didático como um documento histórico e a segunda que os analisa como um produto, uma mercadoria (Choppin, 
2004, p. 554).

Sem descartar a segunda categoria de análise, "onde o historiador dirige sua atenção diretamente para os livros didáticos, recolocando-os no ambiente em que foram concebidos, produzidos, distribuídos, utilizados e recebidos" (Choppin, 2004), analisando especialmente suas formas de produção, editoração, distribuição, em detrimento de seus conteúdos. Neste artigo pretendemos nos voltar para a primeira categoria, que privilegia a análise dos conteúdos dos textos escolares, onde "a história que o pesquisador escreve não é, na verdade, a história dos livros didáticos: é a história de um tema [...], de como a literatura escolar foi apresentada por meio dessa mídia particular" (Choppin, 2004).

Esse trabalho preocupa-se com a maneira como a história do município de Laranjal do Jari é apresentada nos materiais destinados ao ensino de História do Amapá, problematizando e analisando tais narrativas, no intuito de contribuir com as possibilidades dos usos para o ensino da história local do mencionado município. Para isso, nosso texto encontra-se dividido em quatro partes: a primeira, uma discussão sobre o ensino da história local e a contribuição dos materiais didáticos no processo de ensino e aprendizagem; a segunda, uma apresentação e problematização de como a história local do município de Laranjal do Jari é propagada pelos materiais didáticos estudados; a terceira, uma recuperação historiográfica da formação do município de Laranjal do Jari; a quarta, uma proposta alternativa ao ensino de história local que não seja reduzida ao estereótipo vigente aos livros Amapá: vivendo nossa história (2008), escrito por Marcelo André Soares e Maria Emília Brito Rodrigues e História do Amapá: o passado é o espelho do presente (2009), escrito por Paulo Dias Morais.

\section{Ensino da história local e materiais didáticos}

O Ensino de História Local não é uma temática recente na historiografia brasileira, muito pelo contrário, desde as primeiras décadas do século passado este tema tem sido abordado nos debates sobre o Ensino de História no Brasil. Assim sendo, a produção historiográfica sobre a referida temática é recorrente. Para este escrito, pretendemos analisar às produções das últimas duas décadas.

De acordo com as historiadoras Maria Auxiliadora Schmidt e Marlene Cainelli (2009, p. 137), atualmente, na produção historiográfica brasileira, “algumas obras 
indicam um novo enfoque sobre a história local, motivado, principalmente, pelo interesse pela história social", este novo enfoque tem a intenção de "recuperar a história das sociedades como um todo, a história das pessoas comuns".

A partir da Lei de Diretrizes e Bases da Educação Brasileira no 9.394/96 e dos Parâmetros Curriculares Nacionais para o ensino fundamental (1997) e médio (1999), como afirma Schmidt e Cainelli (2009, p. 138), houve maior valorização da história local pelos historiadores, nesse contexto "as atividades relacionadas com o estudo do meio e da localidade são, enfaticamente, indicadas como renovadoras para o ensino da História e salutares para o desenvolvimento da aprendizagem". A LDB № 9.394/96, precisamente no artigo $\mathrm{n}-26$, estabelece como diretriz curricular para todo território nacional:

Os currículos do ensino fundamental e médio devem ter uma base nacional comum, a ser complementada em cada sistema de ensino e estabelecimento escolar por uma parte diversificada, exigida pelas características regionais e locais da sociedade, da cultura, da economia e da clientela (Brasil, 1996, p. 16).

Assim sendo, os currículos devem adotar os conhecimentos comuns ao âmbito nacional, mas também considerar as singularidades dos saberes do lugar de vivência dos alunos e professores.

Os Parâmetros Curriculares Nacionais, elaborados pelo Ministério da Educação para a disciplina de História, dentro do Ensino Fundamental, também discorrem sobre o estudo da história local e regional, corroborando com o direcionamento da LDB anteriormente citado:

A escolha dos conteúdos relevantes a serem estudados, feita neste documento, parte das problemáticas locais em que estão inseridas as crianças e as escolas, não perdendo de vista que as questões que dimensionam essas realidades estão envolvidas em problemáticas regionais, nacionais e mundiais (Brasil, 1997, p. 43).

Os PCN enfatizam que a partir do ensino e aprendizagem da história local os alunos poderão compreender as semelhanças e as diferenças, as permanências e as transformações no modo de vida social, cultural, econômico de sua cidade, no passado e no presente, mediante a leitura de diferentes obras. Ou seja, este ensino contribui 
significativamente para a educação e formação do pensamento histórico do estudante. A historiadora Maria Auxiliadora Schmidt coloca a história local como uma estratégia de ensino, pois

Trata-se de uma forma de abordar a aprendizagem, a construção e a compreensão do conhecimento histórico a partir de proposições que tenham a ver com os interesses dos alunos, suas aproximações cognitivas e afetivas, suas vivências culturais, com as possibilidades de desenvolver atividades vinculadas diretamente com a vida cotidiana, entendida como expressão concreta de problemas mais amplos (Schmidt, 2007, p. 190).

Colocada como método por Geraldo Balduíno Horn e Geyso Dongley Germinari (2010), a história local tem sua importância reafirmada. Os autores apresentam algumas metodologias que podem ser utilizadas para se ministrar essa temática para além dos livros didáticos. Horn e Germinari (2010, p.118) entendem a história local como aquela que desenvolve análises de pequenos e médios municípios e que se trata de uma temática que já vem sendo proposta nos currículos do ensino fundamental brasileiro há pelo menos duas décadas, assumindo diferentes formas de abordagem. De acordo com estes autores

\footnotetext{
Utilizando-se do tempo presente para retroceder ao passado local, regional, nacional e internacional. Isto significa definir ações pedagógicas que privilegiem o tempo vivido do aluno como ponto de partida para outros tempos, estabelecendo assim uma relação do presente com o passado.

Para alcançar essa dimensão no ensino de História é necessário buscar uma estratégia pedagógica que tome o processo histórico local, construído pelas pessoas comuns, como elemento para relacionar as experiências do aluno com questões experimentadas coletivamente, para então buscar articulações com contextos regionais, nacionais e internacionais. Nessa perspectiva, a História Local deixa de ser apenas conteúdo para ser um método de ensino (Horn; Germinari, 2010, p. 142).
}

Utilizando-se das palavras de Maria Cândida Proença, os autores apontam que a história local tem aproveitado as novas metodologias, utilizando-se de novas fontes quantitativas e/ou qualitativas, apresentando temas que poderão ter um aproveitamento didático motivador e estimulante (Proença apud Horn; Germinari, 2010, p. 119). 
Neste contexto, de acordo com Bittencourt (2011, p. 117), é necessário que o aluno desenvolva a capacidade de observação do meio próximo, para que possa atribuir cada vez mais importância aos elementos de sua vivência, tais como a própria moradia, fotografias, artigos de jornais e revistas, considerando-os como objeto de estudo, portadores de informações históricas possíveis de serem recuperadas.

Tanto como conteúdo ou como método, o ensino da história local e regional inserido num contexto amplo permite compreender e alcançar o papel e os objetivos pensados para a história enquanto disciplina escolar. Nesse sentido, a professora Selva Guimarães (2012, p. 114) analisa que devemos "pensar a história como disciplina fundamentalmente educativa, formativa e emancipadora", partindo desta premissa, como disciplina escolar, "seu papel central é a formação da consciência histórica dos homens, possibilitando a construção de identidades, a elucidação do vivido, potencializando a intervenção social, a práxis individual e coletiva". Se o papel central da disciplina História é a formação da consciência histórica, devemos entender melhor esta função.

À priori, faz-se necessário deixar claro o papel da consciência histórica na vida prática dos sujeitos, utilizando as leituras de Maria Auxiliadora Schmidt e Tânia Maria Garcia (2005, p. 301) que colocam a consciência histórica sob função de relacionar o "ser" (identidade) e o "dever" (ação) em uma "narrativa significativa que toma os acontecimentos do passado com o objetivo de dar identidade aos sujeitos a partir de suas experiências individuais e coletivas", com isso, a consciência histórica tem a missão de "tornar inteligível o seu presente, conferindo uma expectativa futura a essa atividade atual". Assim, a consciência histórica tem uma "função prática", função esta que se concretiza em "dar identidade aos sujeitos e fornecer à realidade em que eles vivem numa dimensão temporal, uma orientação que pode guiar a ação, intencionalmente, por meio da mediação da memória histórica". (Schmidt; Garcia: 2005, p. 301)

Consciência histórica é entendida aqui a partir dos argumentos do filósofo alemão Jörn Rüsen, que a conceitua como "a suma das operações mentais com as quais os homens interpretam sua experiência da evolução temporal de seu mundo e de si mesmo, de forma tal que possam orientar, intencionalmente, sua vida prática no tempo" (Rüsen apud Cerri: 2011, p. 30).

Evidenciada a importância da consciência histórica e do ensino de história 
na sua formação, cabe destacar o papel do ensino da história local e regional para que o objetivo central da disciplina história, de acordo com Guimarães (acima citada), seja alcançado, para isto, tomamos mais uma vez as palavras de Maria Auxiliadora Schmidt (2004, p. 182), que aponta que tanto crianças, quanto jovens ou adultos, por intermédio de uma reflexão sobre o local, visto como uma unidade próxima e contígua, podem historicizar e problematizar o sentido de suas identidades, relacionando-se com o mundo de forma crítica, a partir do local, da formação da consciência histórica, podem mudar, ou não, como sujeitos, a própria vida.

Dito isto, afirmamos que o ensino da história local desempenha um papel muito importante na formação da consciência histórica dos alunos, sem contar que, concordando com os argumentos de Jaime Pinsky e Carla Bassanezi Pinsky (2003, p. 28), quanto mais o aluno sentir a História próxima a ele, não como uma coisa externa e distante, mais se sentirá qualificado e inclinado a exercer seu papel de sujeito, de agente histórico.

É sabido que o ensino de história local sempre esteve presente nos debates e diretrizes educacionais brasileiros, seja como conteúdo ou como método. Contudo, como nos assevera Guimarães (2012, p. 239), apesar das diretrizes e dos consensos construídos sobre a importância do estudo da história local e regional para a formação de crianças e jovens, ainda nos deparamos, no cotidiano escolar, com uma série de dificuldades para a prática deste ensino, uma das dificuldades apontadas diz respeito à disponibilidade de materiais didáticos.

No primeiro capítulo da sua dissertação de mestrado, Flávio Batista dos Santos discute sobre o Ensino da História Local na Educação Básica, iniciando sua argumentação pelo lugar que o Local ocupa na historiografia e no currículo brasileiro, nesse ínterim aponta as dificuldades que o ensino da história local enfrenta, mais especificamente nas séries finais do ensino fundamental e no ensino médio.

Santos afirma que,

Para as séries iniciais do ensino fundamental é comum se encontrar materiais e livros didáticos voltados para o ensino da história local, ainda que os conteúdos sejam apresentados de maneira generalizante. Mas para as séries finais e para o ensino médio, os recursos didáticos referentes ao ensino e aprendizado da história local são escassos, já que os livros são definidos a partir de uma avaliação nacional, 
as particularidades locais quase sempre ficam de fora, em segundo plano, isto acaba restringindo o trabalho do professor, reduzindo o local a ações esporádicas e particulares por parte dos professores, já que não contam com um material didáticos à disposição para utilizar em suas aulas (Santos: 2014, p. 26).

Já fora apresentado anteriormente outras maneiras de se trabalhar com a história local para além dos livros didáticos, como propuseram Horn e Germinari (2010, p.135), a partir de arquivos familiares, por exemplo. Assim sendo, "o livro didático é uma fonte útil desde que não seja considerado o lugar de toda a História" (Guimarães: 2012, p. 106), ou seja, o livro didático é uma importante ferramenta, mas não é a única. Contudo, como aponta Maria Laura P. B. Franco, apesar de deixarem a desejar em muitos aspectos, os livros didáticos acabam sendo adotados porque o professor, obrigado a lecionar o dia todo em com um volume muito grande de provas para corrigir, não tem tempo para preparar seus próprios textos, aceitando a comodidade de contar com um material pronto para ser utilizado (Franco: 1982, p. 15).

Segundo Bittencourt, os livros didáticos são os instrumentos de trabalho mais utilizados por professores e alunos sendo muito fácil diferenciá-los dos demais livros, contudo, de difícil definição, pois trata-se de um objeto de "múltiplas facetas", cujo processo de produção, circulação e consumo sofrem interferência de inúmeros sujeitos (Bittencourt: 2011, p. 301). A autora acrescenta às múltiplas facetas que o livro didático possui ao serem analisadas: como suporte de conhecimentos escolares propostos pelos currículos educacionais; também como mercadoria; como veículos de um sistema de valores; etc. (Ibidem, p. 301-306).

Corroborando e utilizando as próprias palavras de Bittencourt (1993) e Kazumi Munakata (1994), entre outros autores e autoras, Décio Gatti Júnior define o livro didático da seguinte forma:

Material impresso, estruturado ou adequado a ser utilizado num processo de aprendizagem ou formação; materiais caracterizados pela seriação dos conteúdos; mercadoria; depositário de conteúdos educacionais; instrumento pedagógico; portador de um sistema de valores; suporte na formulação de uma História Nacional; fontes de registros de experiências e de relações pedagógicas da época; e ainda como materiais reveladores de ângulos do cotidiano escolar e do fazerse da cultura nacional (Gatti Júnior: 2004, p. 34-35). 
Como podemos perceber, trata-se de um objeto multifacetado, que precisar ser contextualizado e analisado considerando essas múltiplas facetas. Com relação aos paradidáticos, de acordo com Ernesta Zamboni (1991), considera-se, na visão dos editores, as publicações que têm como objetivo subsidiar o trabalho docente, diferenciando-se do livro didático não em conteúdo, mas em forma. Esta denominação - paradidático, segundo Zamboni, apareceu em catálogos editoriais no final da década de 1970 (Zamboni, 1991, p. 11)

Kazumi Munakata (1997) caracteriza os livros paradidáticos como livros que diferem de um livro didático na estrutura de apresentação do conteúdo, mas são adotados no processo de ensino e aprendizagem nas escolas, seja como material de consulta do professor, seja como material de pesquisa e de apoio às atividades do educando (Munakata, 1997, p. 103).

Gatti Júnior (2004) ratifica o exposto por Zamboni (1991) e Munakata (1997) apontando que, em finais da década de 1970, os chamados paradidáticos eram pequenos livros, com temas único, empregados como auxílio do processo de ensino, para além do livro didático (Gatti Júnior, 2004, p. 167). O autor afirma que para atender à demanda referente ao estudo e ao ensino da História Regional/Local, os livros paradidáticos foram uma opção, especialmente antes do surgimento dos livros didáticos regionalizados (Gatti Júnior, 2004, p. 209

Os livros didáticos, em vias de regra, são produzidos para o mercado nacional, Gatti Júnior (2004) mostra que isto é preocupante, inclusive para os próprios autores de livros didáticos, como o demonstrado nas palavras de alguns entrevistados ao pensarem sobre as diversidades regionais brasileiras: "quando fico sabendo que o meu livro está sendo adotado no Amazonas, fico pensando se realmente seria o livro mais indicado para o Amazonas, porque eu não conheço a realidade do Amazonas" (Faria; Berutti apud Gatti Júnior, 2004, p. 208). Gatti Júnior acrescenta:

Há dificuldades enormes, mas também alguns avanços em diversos Estados brasileiros, com o desdobramento da pesquisa regional, têm sido possíveis a produção de livros didáticos que abordam com propriedade as questões e especificidades locais [...] mas antes mesmo desta tendência em produção de livros regionalizados aparecer, estavam consolidados no mercado brasileiro os chamados livros paradidáticos que, para alguns editores, poderiam suprir essa carência por 
textos regionalizados (Gatti Júnior, 2004, p. 209).

São poucas as cidades brasileiras que contam com livros didáticos destinados ao ensino da História Local, os títulos sobre a história regional são encontrados com mais facilidade, como no caso do Amapá, com os livros sobre a história regional Amapá: vivendo nossa história (2008 e 2011); e títulos paradidáticos como História do Amapá: o passado é o espelho do presente (2009 e 2011) que constituem os objetos de análise deste artigo a partir de agora.

\section{A "maior favela fluvial do mundo" nos materiais didáticos de história do Amapá}

Ao se iniciar o ano de 2008, a Assembleia Legislativa do Estado do Amapá (ALAP) aprovou a lei no 1.183 (referente ao projeto de lei $n$ 우 0115/2007), de autoria do deputado Manoel Mandi, autorizando o Poder Executivo a instituir no Ensino Fundamental e/ou Médio da rede pública estadual de ensino a disciplina de História do Amapá. O objetivo da criação da disciplina consiste em formar cidadãos conscientes da identidade, potencial e valorização do nosso Estado, para isto, permanecendo na parte diversificada do currículo, o conteúdo poderia ser disposto em uma série determinada ou distribuído em várias séries.

Com o exposto na lei, verificou-se a necessidade de se desenvolver materiais didáticos para tornar mais viável a comunicação dos conteúdos aos alunos e o alcance dos objetivos propostos para a disciplina. Diante desta demanda, no mesmo ano foi publicado o livro didático intitulado Amapá: vivendo nossa história (2008), de autoria do professor de história Marcelo André Soares e da pedagoga Maria Emília Brito Rodrigues, este livro fora reeditado em 2011, adquirido pelo PNLD - Programa Nacional do Livro Didático do MEC - Ministério da Educação e distribuído para as escolas estaduais e municipais para serem utilizados nos anos letivos de 2013, 2014 e 2015.

O livro é composto por 128 páginas, dividido em sete unidades de estudo que abordam vários aspectos da história do Amapá como a presença indígena e africana, a organização amapaense na época da colonização brasileira, a criação do Território Federal do Amapá, o Amapá após se transformar em Estado e na atualidade, enfatizando aspectos políticos, econômico, sociais e culturais desse processo histórico. Dentro das unidades encontramos algumas narrativas sobre a história de alguns municí- 
pios amapaenses como Mazagão, Oiapoque, Serra do Navio, Santana, Laranjal do Jari, etc.

Tal material didático fora recebido com entusiasmo no município de Laranjal do Jari, contudo, em uma reunião para leitura e planejamento com professores da disciplina de História e Oficina de Trabalho, que contemplavam em suas matrizes curriculares os conteúdos de História do Amapá, observou-se inúmeras lacunas e superficialidades nos textos apresentados por Soares e Rodrigues.

A narrativa apresentada contribui para a legitimação de alguns estereótipos, como por exemplo, ao abordar a formação do município de Laranjal do Jari, os autores ainda se referem a ele pelo antigo nome de "Beiradão", e limitam suas argumentações a três parágrafos, colocando a constituição da vila como um problema social causado pela implantação do Projeto Jari, enfatizando as condições precárias em que a vila foi criada, caracterizando-a como uma verdadeira "favela sobre o rio".

Quanto ao aspecto social, o maior problema provocado pelo Projeto Jari foi a ocupação desordenada da região por migrantes de todas as partes do país, principalmente do Norte e Nordeste, que foram para lá em busca de emprego. Como grande parte desses migrantes não conseguiu o tão sonhado emprego, o resultado foi a formação de um enorme aglomerado de casebres conhecido como Beiradão, às margens do rio Jari em condições precárias.

O contraste que existe no local é muito evidente: numa margem do rio Jari estão as palafitas do Beiradão e na outra margem as casas pré-fabricadas feitas para funcionários do Projeto Jari.

Além das condições miseráveis, o desemprego na região provocou, também, outros sérios problemas como os altos índices de violência, a prostituição e inúmeras doenças provocadas pelas precárias condições de saneamento básico, tornando a região uma verdadeira "favela sobre o rio" (Soares; Rodrigues, 2011, p.76-77).

Esta narrativa, contida na quinta unidade do livro em questão, precisamente no subtema - O Projeto Jari: riqueza e miséria no Amapá - permite questionar uma série de elementos, dentre eles: qual a representação desse discurso no imaginário social da ou sobre a cidade?; como ela pode influenciar na formação da consciência histórica dos alunos?; a construção desse estereótipo é corroborada por outros meios de comunicação e difusão do saber?

Este último questionamento pode ser facilmente respondido, pois Laranjal do Jari é retratado em inúmeras outras narrativas como uma enorme favela fluvial 
surgida como consequência social de um empreendimento empresarial implantado na região ao final da década de 1960. Em um livro paradidático intitulado História do Amapá: o passado é o espelho do presente, de autoria de Paulo Dias Morais, publicado no ano de 2009 e reeditado em 2011, a história de Laranjal é retratada da seguinte forma:

O Projeto Jari [...] por se tratar de um projeto grandioso, necessitava de bastante mão-de-obra. Muitos trabalhadores se dirigiram para lá visando melhores condições de vida. Uma grande parte dos trabalhadores eram contratados temporariamente por empreiteiras que não asseguravam os direitos trabalhistas, quando eram dispensados pela companhia. Estes não dispunham de recursos para moradia e nem para retornarem aos seus locais de origem.

Por isso, a maioria foi obrigada a viver às margens do Rio Jari e Vitória do Jari, em palafitas sem as mínimas condições de higiene. Isso fez com que surgissem áreas como: 'Beiradão e Beiradinho' que se tornaram as maiores favelas fluviais do mundo, sendo uma das mais pobres e violentas da população brasileira. A prostituição chegou a índice alarmante e, para completar essas áreas passaram pelo esquecimento do governo por muito tempo. (Morais, 2011, p. 94 e 95)

Podemos notar que tanto a produção didática como a paradidática acima citadas apresentam narrativas semelhantes ao se referirem ao surgimento do município de Laranjal do Jari, o que leva as seguintes questões: quais fontes os autores utilizaram?; como foi instituído o estereótipo de "maior favela fluvial do mundo"? Na tentativa de responder a tais interrogações cabe conhecer um pouco mais a historiografia sobre a formação do município.

\section{A dita "maior favela fluvial do mundo": um breve histórico sobre o município de Laranjal do Jari}

Laranjal do Jari é uma cidade situada ao norte da Amazônia Brasileira, precisamente sudoeste do Estado do Amapá, distante cerca de $265 \mathrm{~km}$ da capital, Macapá. Atualmente, constitui o 3o maior município do Estado, com uma população estimada em torno de 47.000 habitantes (dados do IBGE/2016). Foi criado oficialmente através do Decreto no 7.639, publicado em 17 de dezembro de 1987, que o desmembrou do município de Mazagão, com o qual faz limite, além dos municípios de Oiapoque, Pedra Branca do Amapari, Almeirim (Estado do Pará), e territórios internacionais como Guia- 
na Francesa e Suriname. Segundo a professora Sônia Maria Clareto (2003),

\begin{abstract}
A ocupação da região Laranjal do Jari teve início com holandeses e ingleses que, em busca de especiarias, subiam o rio Amazonas. O local fora praticamente esquecido pelos portugueses até que, em 1623, começou uma longa batalha para expulsar os estrangeiros. Padres jesuítas e franciscanos tiveram um forte envolvimento na ocupação da região, fundando conventos e catequizando indígenas. Também os nordestinos desempenharam aí importante papel, sobretudo no auge do ciclo da borracha, entre 1872 e 1920 (Clareto, 2003, p. 83)
\end{abstract}

De acordo com o escritor Cristóvão Lins (2001), dentre os nordestinos que desempenharam papel importante na ocupação da região, é importante destacar a pessoa de José Júlio de Andrade, o cearense que aos 28 anos de idade já era considerado o maior comerciante da região do Jari e um dos maiores latifundiários do mundo, proprietário de cerca de três milhões de hectares de terras, com propriedades nos municípios de Almeirim e Porto de Moz (no Estado do Pará) e Mazagão (Laranjal e Vitória do Jari no Estado do Amapá).

Segundo Anna Greissing (2011), a região do Jari se caracteriza por uma floresta primária tropical muito rica em recursos naturais, principalmente a castanha do Pará (bertholletia excelsa) e a seringa (hevea brasiliensis), cuja exploração sempre constituiu a fonte principal de subsistência para as populações extrativistas. Já nos tempos da colonização, os missionários instalados na região do Jari enriqueciam-se com a comercialização das "drogas do sertão".

A organização da atividade extrativista no Jari, em uma comercialização no estilo de uma empresa, desenvolveu-se a partir do final do século XIX, com a aparição na região do cearense José Júlio de Andrade, em 1882, em pleno apogeu do ciclo da borracha (Greissing, 2011, p. 46). Mesmo quando o ciclo da borracha começou a declinar, entre 1907 e 1920, ele se manteve como forte comerciante, pois tinha atividades econômicas também na pecuária e na coleta de castanha (Clareto, 2003, p. 83).

José Júlio adquiriu o título honorífico militar do Exército de "Coronel da Guarda Nacional". Elegeu-se Senador da Câmara de Belém, com sucessivos mandatos, tornando-se um homem extremamente influente no campo político, social e econômico do Baixo Amazonas, até a revolução de 1930, quando o Tenente Magalhães Barata, Interventor Federal no Pará, declarou o "coronel" como inimigo, devido o mesmo ser 
amigo do jornalista Paulo Maranhão, desafeto de Barata. Este fato o obrigou a vender sua empresa Jari para um grupo de empresários portugueses, em 1948. Posteriormente a empresa foi vendida para Daniel Keith Ludwig.

Desde a época de José Júlio, a região do Jari era habitada por pequenas comunidades locais disseminadas pela floresta, no entanto, como constata Regina Ferreira (2008, p. 79), a intervenção do "coronel" não foi tão marcante quanto a do empresário norte americano Daniel Ludwig, que liderou a instalação do Complexo Industrial Jari.

O objetivo deste empresário era construir, em plena selva, um gigantesco pólo industrial, substituindo a floresta nativa por uma floresta homogênea para abastecer o mercado internacional de celulose, bem como exportar em grande escala a carne bovina, o arroz e o caulim. Para alcançar os objetivos propostos, a empresa precisaria de muitos trabalhadores, o que atraiu milhares de imigrantes para a região. Para Clareto,

Existem diferentes versões para as origens de Laranjal do Jari, mas todas concordam que o surgimento da cidade estaria atrelado ao empreendimento do empresário americano Ludwig e a Monte Dourado. Assim, o início da ocupação daquele espaço às margens do Jari teria acontecido como opção para aqueles que haviam se deslocado para a região em busca de emprego e melhores condições de vida. Houve um grande deslocamento de pessoas para a região com essa intenção, sobretudo nordestinos - do Maranhão, Piauí e Ceará, principalmente - e nortistas de outras localidades. Como não havia emprego para todos, muitos, sem condições de voltarem para seus locais de origem, acabavam ficando e ocupando um local à beira do rio Jari para habitar temporariamente, na margem oposta a Monte Dourado, no estado do Amapá (antigo Território do Amapá), em terras que pertenciam a Ludwig e seu Projeto (Clareto, 2003, p. 86).

De fato, com a implantação da empresa Jari Celulose, entre as décadas de 1960 e 1970, com sede em Monte Dourado, no município de Almeirim-PA, estimulou a migração, principalmente da região norte e nordeste, propiciando o crescimento populacional da área sul do Estado do Amapá, em concentrações como o da "Vila do Beiradão" (margem esquerda do rio Jari), área fronteiriça de Monte Dourado. É importante ressaltar que a cidade de Monte Dourado foi projetada e construída, especificamente, para atender os funcionários da empresa, com toda a infraestrutura que as cidades no 
padrão norte americano possuíam. De acordo com Ferreira,

\begin{abstract}
O marco de sua formação foi no ano de 1967 quando ocorre o levantamento dos primeiros barracos, erguidos com finalidade de atender pessoas que estariam ligadas à empresa. Em 1968 a empresa autorizou a construção da Vila do Pau Roliço acampamento próximo de Monte Dourado que abrigou alguns empregados, ex-empregados ou recém-admitidos da Jari. Nesse momento o número de casas era bem reduzido, existiam 26 casas, nas quais residiam 229 pessoas, mesmo a Jari tendo autorizado o acampamento, os moradores não eram bem vistos, isso ocorreu em razão das condições da falta de higiene e insalubridade que existiam no local (Ferreira, 2008, p. 80).
\end{abstract}

A Vila do Pau Roliço chegou a ser derrubada, a mando da empresa, contudo, do outro lado do rio, em frente a Monte Dourado, iniciou-se a construção de um novo povoado, à revelia da Jari. Com o crescimento do povoado, em 1971, iniciou-se a formação de um pequeno núcleo urbano que, situado à margem esquerda do Rio Jari, passou a ser chamado de "Beiradão".

Em menos de dez anos, o número de habitantes do Beiradão já somava o dobro de habitantes de Monte Dourado, “em 1977, enquanto Monte Dourado tinha 2.096 habitantes, no Beiradão já existiam 5 mil [...]. Em 1983 no Beiradão moravam 12 mil pessoas e em Monte Dourado 8.500" (Ferreira, 2008, p. 82), nesta época a Vila do Beiradão crescia muito rapidamente, com isso a realidade passou a ser outra, pois passou a chamar a atenção do poder público que, em 1987, elevou a Vila do Beiradão à categoria de Município de Laranjal do Jari.

Os objetivos de Ludwig em relação ao seu mega empreendimento não foram alcançados devido, principalmente, à improdutividade das plantações. Em 1982, o americano viu-se obrigado a abandonar o projeto sem resultados satisfatórios e, com a sua saída, a empresa passou a ser gerida pelo grupo CAEMI (Companhia Auxiliar de Empresas e Mineração), uma corporação de empresários brasileiros e estrangeiros, dirigida pelo português Augusto Trajano de Azevedo Antunes. Contudo, sob essa gestão, a empresa também não caminhou conforme o desejado. Apesar de generosas intervenções do BNDES, o projeto encontrou-se próximo à falência total em 1997, mas em 1999 foi adquiro pelo Grupo Orsa, dirigido pelo empresário brasileiro Sérgio Amoroso. De acordo com Anna Greissing, 
Os objetivos da nova empresa na direção do projeto são principalmente dois: levar a produção de celulose a uma viabilidade econômica (a partir de importantes investimentos e inovações técnicas visando também à redução dos impactos ambientais), e restabelecer a legitimidade do projeto frente aos atores da política e da sociedade civil. Para isso, a empresa cria uma Fundação (a Fundação ORSA) inspirada nos princípios da responsabilidade social e ambiental, que desde 2000 compromete-se com o desenvolvimento de pequenos projetos econômicos e sociais junto a populações locais (Greissing: 2011, p. 45).

Para concretizar este segundo intuito acima citado, a Fundação Orsa contratou uma equipe de pesquisadores, da qual fez parte a professora Sônia Maria Clareto, que visitou o município de Laranjal do Jari nos anos 2000. Clareto afirma que, antes de saírem a campo, "ouvimos muitas histórias acerca da maior favela fluvial do mundo, como Laranjal é considerada pela imprensa em geral e por algumas pessoas que moram na região, mais especificamente em Monte Dourado" (Clareto: 2003, p. 70).

Sua pesquisa sobre o referido município resultou em sua tese de doutorado, "Terceiras Margens: um estudo etnomatemático de espacialidades em Laranjal do Jari (Amapá)", defendida no ano de 2003, nela a autora afirma que o estereótipo de "maior favela fluvial do mundo" que recai sobre o município foi instituído pela imprensa (Clareto, 2003, p. 65).

A afirmação da autora de que a imprensa é a responsável pela propagação do estereótipo que caracteriza a parte baixa do município de Laranjal do Jari como a "maior favela fluvial do mundo", se fundamenta em uma pesquisa documental, realizada pela equipe antes da saída à campo, junto à imprensa sobre o Projeto Jari, envolvendo documentos desde a década de 1970 até os dias atuais. A pesquisa foi realizada na imprensa brasileira e internacional e cobriu revistas como Visão, Movimento, Pasquim, Veja, Isto É, e jornais como Folha de São Paulo, Estado de São Paulo, O Liberal do Pará, Gazeta Mercantil; entre outros títulos internacionais, o Herald Tribune (Clareto, 2003).

Órgãos oficiais do Governo Federal, como o IBGE (Instituto Brasileiro de Geografia e Estatísticas) também corroboram o estereótipo instituído pela imprensa. Ao se referir ao histórico do município de Laranjal do Jari, na página oficial da internet, o Instituto aponta que, a região que hoje corresponde o Vale do Jarí foi habitada, primeiramente por indígenas Wayana e Apalai e, mais tarde por nordestinos que vieram 
trabalhar na extração da borracha.

Dentre esses nordestinos destacou-se um cearense chamado José Júlio de Andrade, também conhecido como Coronel Zé Júlio, que se consolidou como o maior latifundiário do mundo, adquirindo cerca de 3,5 milhões de hectares de terra. Foi combatido pela revolta tenentista, fato que o obrigou a vender sua empresa Jarí para um grupo de empresários portugueses, em 1948. Posteriormente a empresa foi vendida para o milionário norte americano Daniel Ludwig.

Suas origens remontam à época da colonização do rio Jarí, recebendo ainda influências mais recente da implantação do projeto Jarí Florestal, em 1967 idealizado por Ludwig. Este pretendia substituir a floresta nativa por uma plantação homogênea de uma planta denominada gmelina arbórea para a fabricação de celulose, e também pretendia torna-se o maior produtor mundial de carne bovina, suína e arroz.

Como se tratava de um projeto de grande porte, a empresa necessitava de bastante mão de obra. Motivado pelo afã nacionalista (década de 60) e visando melhores condições de vida, muitos trabalhadores dirigiram-se para a região. Boa parte foi contratada de forma temporária e indireta, por empreiteiras, que não Ihes asseguravam os direitos trabalhistas.

Dispensados pela companhia, não dispunham de recursos nem para moradia, tampouco para retornar aos seus locais de origem. A maioria foi obrigada a viver às margens do rio, em palafitas, sem as mínimas condições de higiene e sobrevivência. Isto fez com que o "Beiradão" se tornasse conhecido como "a maior favela fluvial do mundo", além dos altos índices de prostituição também foi considerada uma das mais pobres e violentas populações brasileiras.

A narrativa apresentada pelos IBGE coloca o município de Laranjal do Jari como uma imensa favela fluvial, e acaba por influenciar as narrativas apresentadas pelos livros didático e paradidático mencionados anteriormente.

\section{A "maior favela fluvial do mundo" nos materiais didáticos de história do Amapá: o ensino da história local do município Laranjal do Jari}

Tanto a narrativa apresentada por Marcelo André Soares e Maria Emília Brito Rodrigues (2008) quanto a de Paulo Dias Morais (2009) é permeada de estereótipos que perduram no senso comum desde finais da década de 1970 . O conceito de 
estereótipo é entendido a partir da ideia defendida por Maria Aparecida Baccega, que refere-se a "generalizações que as pessoas fazem a partir de imagens preconcebidas, um reflexo ou refração da realidade que traz em si juízo de valor e preconceitos". A conceituação de estereótipo proposta pela autora evidencia o seu significado como pré-juízo, na maioria das vezes absorvido como senso comum e transmitido de geração a geração (Baccega, 1998, p. 7-14). Retomou o debate do 2.

Este conceito é corroborado pelo historiador britânico Peter Burke na obra Testemunha Ocular: História e Imagem (2004). A obra propõe um incentivo às possibilidades de uso de gravuras, pinturas e fotografias como fontes documentais da pesquisa histórico-cultural, com isso dedica um capítulo para problematizar as visões estereotipadas do "Outro" registradas através das imagens. Trata-se do sétimo capítulo da obra - Estereótipos do Outro - em que o autor analisa a ligação entre as imagens mentais e visuais que pré-concebemos, salientando que:

\footnotetext{
Quando ocorrem encontros entre culturas, é provável que a imagem que cada cultura possui da outra seja estereotipada. A palavra "estereotipo" (originalmente uma placa da qual a imagem podia ser impressa), como a palavra clichê (originalmente o termo francês para a mesma placa) é um sinal claro da ligação entre imagens visuais e mentais. $O$ estereótipo pode não ser completamente falso, mas frequentemente exagera alguns traços da realidade e omite outros. $\mathrm{O}$ estereótipo pode ser mais ou menos tosco, mais ou menos violento [...] (Burke, 2004, p. 155-156).
}

Esta afirmação de Burke se faz presente na narrativa apresentada sobre o município de Laranjal do Jari no livro didático Amapá: vivendo nossa história, pois trata-se de uma argumentação verídica, mas que não dá conta da construção histórica do município (deixa de lado fatos, sujeitos, características políticas, sociais, culturais e econômicas) e dão importância aos aspectos negativos.

Segundo Burke, "infelizmente a maioria dos estereótipos de outros - judeus vistos por não-judeus, muçulmanos por cristãos, negros por brancos, camponeses por pessoas da cidade, [...] etc._era ou é hostil, desdenhosa ou, no mínimo, condescendente" (Burke, 2004, p. 157), no caso do município de Laranjal do Jari, percebido em contraste com o distrito de Monte Dourado, a narrativa apresenta características deste desdém, principalmente no discurso da primeira edição do livro, do ano de 2008, 
em que um texto complementar evidencia os aspectos mais violentos da oposição entre os dois locais em questão:

Em Monte Dourado, vive-se o "primeiro mundo", em casas com grama aparada, quadra de esportes, loja de cosméticos, escola de informática e escritório de companhia aérea. No Beiradão, onde moram quatro, em cada cinco habitantes do Laranjal, estampa-se o retrato do "terceiro mundo" nas dezenas de palafitas cercadas por antenas parabólicas e erguidas sobre um tapete de água fétida onde os moradores despejam seu esgoto e as crianças se refestelam. Quando a noite cai, os bares e boates patrocinam uma guerra de decibéis, luz colorida e muita cachaça. [...] (Revista Isto É, 13 de julho de 2002 apud Rodrigues; Soares, 2008, p. 77).

A professora Kátia Maria Abud (1984), alerta para o cuidado com as narrativas estereotipadas que os livros didáticos destinados ao ensino de História podem conter, pois "o livro didático tem sido um dos mais utilizados canais de transmissão e, sobretudo, de manutenção dos mitos e estereótipos que povoam a História do Brasil" (Abud, 1984, p. 81).

Franco (1982) afirma que os conteúdos transmitem valores, crenças e as visões de mundo dos autores que o produzem, e isto é absorvido pelo aluno, daí a importância em considerar que os livros didáticos podem funcionar como instrumentos de reprodução ideológica (Franco, 1982, p. 17-18). Assim sendo, as narrativas apresentadas pelos livros didáticos sempre devem ser problematizadas, pois, de acordo com Guimarães, a difusão de determinada narrativa histórica "pode tornar definitivas, institucionalizadas e legitimadas determinadas visões e explicações históricas" (Guimarães, 2012, p. 97).

Contudo, mesmo que a narrativa presente nos livros didáticos e paradidáticos aqui estudados apresentem a história do município de Laranjal do Jari ressaltando suas caraterísticas pejorativas, é possível que o (a) professor (a) os utilize como base para excelentes aulas.

Como já foi dito, concordamos com o que aponta a professora Selva Guimarães,

O livro didático é uma fonte útil para toda a cultura escolar, desde que não seja considerado o lugar de toda história. Submetido à leitu- 
ra crítica, com a ajuda interpretativa do professor e colocado em diálogo com outras fontes de estudo - acervos de museus e arquivos, livros não didáticos, produção literária e artística, por exemplo, ele pode contribuir de modo significativo para a aprendizagem histórica (Guimarães, 2012, p. 106).

O fato é que todo livro didático (e/ou paradidático), precisa ser visto como um instrumento a mais dentro do processo de ensino e aprendizagem. Em sala de aula, como qualquer outra fonte, os livros precisam ser ampliados, complementados, criticados e revistos. Para que isso aconteça, assevera Guimarães, "o professor deve ter uma posição crítica, nunca de submissão em relação ao livro de História que, como todo texto, toda fonte, merece ser questionado, problematizado e amplamente explorado com os alunos" (Guimarães, 2012, p. 107).

Desta feita, ao se utilizar do livro didático Amapá: vivendo nossa história (Soares; Rodrigues, 2008) e o paradidático História do Amapá: o passado é o espelho do presente (Morais, 2009), para trabalhar o ensino da história local do município de Laranjal do Jari, o (a) professor (a) deve considerar: outras fontes sobre a narrativa apresentada; a origem do estereótipo de "maior favela fluvial do mundo"; o contexto em que a vila do Beiradão surgiu, como surgiu, como se desenvolveu, como se transformou no terceiro maior município do Estado do Amapá; entre outros fatores. Para isso, o (a) professor (a) precisa contextualizar a temática e fomentar a pesquisa histórica dos alunos em jornais, revistas, fotografias, arquivos familiares, fontes orais, etc.

As narrativas apresentadas pelos livros acima citados precisam ser problematizadas e criticadas pelos alunos que, quando em contato com outras fontes de conhecimento sobre o assunto, podem construir suas próprias opiniões. A respeito disto, Guimarães acrescenta que,

O processo de renovação nos livros didáticos e a ampliação do mercado de paradidáticos nos levam a concluir que as empresas editoriais tornaram-se, nas últimas duas décadas, agentes poderosos na definição sobre o que ensinar em História e como ensiná-las na escola fundamental. $O$ ensino de História é um espaço complexo, no qual atuam diferentes propostas de saber e poder, cabendo aos professores desta disciplina o papel fundamental de desenvolver um ensino que contribua para a formação do pensamento crítico e reflexivo, para a construção da cidadania e a consolidação da democracia entre nós [...]. Nem tudo é o livro didático: o ensino se dá por múltiplos caminhos; [...] O livro didático é uma fonte importante, mas não deve 
ser a única.

Quando problematizados e trabalhados em conjunto com outras fontes do conhecimento histórico, os livros citados neste artigo podem estimular a formação do pensamento crítico e reflexivo dos alunos. Para isso, destacamos o papel do professor em sala de aula, para que, de fato, o ensino de História fomente a formação de sujeitos livres, cidadãos capazes de refletir sobre o mundo no qual vivem e o mundo no qual querem viver.

\section{Considerações Finais}

Através da leitura deste escrito, pode-se constatar que os livros didáticos e paradidáticos são instrumentos pedagógicos valiosos dentro do processo de ensino e aprendizagem, constituem suportes privilegiados dos conteúdos educativos que, por mais que propaguem estereótipos, trata-se de um recurso válido, que não precisa ser, necessariamente, rejeitado e descartado pelo professor.

Salientamos que o livro didático ideal, aquele que possa atender a todos os critérios avaliativos e qualitativos, agradando a toda clientela de professores, não existe. Assim, ao invés do descarte, reiteramos que tais materiais podem servir de suporte para excelentes aulas, desde que utilizados com cautela e criticidade pelo professor.

O ensino da história local do município de Laranjal do Jari pode ser viabilizado através dos livros didático e paradidático que aqui analisamos, desde que a metodologia do professor possa problematizar as narrativas apresentadas, no objetivo de fomentar uma postura crítica e reflexiva de seus alunos e contribuir para a construção de sua consciência histórica,

\section{REFERÊNCIAS}

ABUD, Kátia Maria. O Livro Didático e a Popularização do Saber Histórico. In: SILVA, M. Repensando a História. São Paulo: Anpuh/Marco Zero, 1984.

AMAPÁ, Assembleia Legislativa do Estado. Lei 1183/2008.

BACCEGA, Maria Aparecida. O estereótipo e as diversidades. Comunicação \& Educação, São Paulo, n. 13, p. 7-14, dec. 1998. ISSN 2316-9125. Disponível em: <http://www.revistas.usp.br/comueduc/article/view/36820>. Acesso em: 31 oct. 2016.

BITTENCOURT, Circe Maria Fernandes. Ensino de História: Fundamentos e Métodos. São Paulo: Cortez, 2011. 4 ed.

BRASIL, Ministério da Educação. Lei de Diretrizes e Bases da Educação no 9.394/96. 
BRASIL, Ministério da Educação. Parâmetros Curriculares Nacionais: História e Geografia. Secretaria de Educação Fundamental. Brasília: MEC, 1997.

BURKE, Peter. Testemunha ocular: história e imagem. Bauru: EDUSC, 2004.

CERRI, Luis Fernando. Ensino de História e Consciência Histórica. Rio de Janeiro: Editora FGV, 2011.

CLARETO, Sônia Maria. Terceiras margens: um estudo etnomatemáticos de espacialidades em Laranjal do Jari (Amapá). Tese (Doutorado em Educação Etnomatemática, orientada pelo Prof. Dr. Ubiratan D’Ambrósio). Universidade Estadual Paulista, Rio Claro-SP. 2003.

CHOPPIN, Alain. História dos livros e das edições didáticas: sobre o estado da arte. Revista Educação e Pesquisa, São Paulo, v.30, n.3, p. 549-566, set./dez. 2004

FERREIRA, Regina Célis Martins. Cidade de Laranjal do Jari: expansão urbana, planejamento e políticas públicas. Dissertação (Mestrado em Desenvolvimento Regional, orientada pelo Prof. Dr. José Alberto Tostes). Universidade Federal do Amapá - Macapá, 2008.

FRANCO, Maria Laura P. B. O Livro Didático de História no Brasil: a versão fabricada. São Paulo: Global Editora. 1982.

GATTI Júnir, Décio. A Escrita Escolar da História: livro didático e ensino no Brasil (19701990). Bauru, SP: Edusc; Uberlânida, MG: Edufu, 2004.

GONÇALVES, Márcia de Almeida. História Local: o reconhecimento da identidade pelo caminho da insignificância. In: MONTEIRO, Ana Maria. GASPARELHO, Arlette Medeiros. MAGALHÃES, Marcelo de Souza (orgs.). Ensino de História: Sujeitos, Saberes e Práticas. Rio de Janeiro. Mauad X: FAPERJ, 2007.

GREISSING, Anna. A Região do Jari, do extrativismo ao agronegócio: as contradições do desenvolvimento econômico na Amazônia Florestal no exemplo do Projeto Jari. Revista de Estudos Universitários da Universidade de Sorocaba, 2011, 36 (3), pp.20-37. Disponível em https://halshs.archives-ouvertes.fr/halshs-00560647. Acesso em 12 nov. 2016.

GUIMARÃES, Selva. Didática e Prática de Ensino de História. São Paulo: Papirus, 2012, 13 ed.

Histórico do Município de Laranjal do Jari. IN: INSTITUTO BRASILEIRO DE GEOGRAFIA E ESTATÍSTICAS:

http://cidades.ibge.gov.br/painel/historico.php?lang=\&codmun=160027\&search=ama pa|laranjal-do-jari|infograficos:-historico. Acessado em 12 de ago. de 2016.

HORN, Geraldo Balduíno. GERMINARI, Geyso Dongley. O Ensino de História e seu currículo: teoria e método. Rio de Janeiro: Vozes, 2010. 3 ed.

LINS, Cristóvão. A Jari e a Amazônia. Rio de Janeiro, Dataforma e Prefeitura de Almeirim-PA. 3a ed, 2001.

MORAIS, Paulo Dias. História do Amapá: o passado é o espelho do presente. JM Editora Gráfica, Macapá - Amapá. 2009.

MUNAKATA, Kazumi. Produzindo livros didáticos e paradidáticos. História e Filosofia da Educação. Tese (Doutorado em História e Filosofia da Educação, orientado pela Profa. Dra. Mirian Warde). PUC-SP, 1997.

PINSKY, Jaime. PINSKY, Carla Bassanezi. Por uma História Prazerosa e Consequente. In: KARNAL, Leandro (org.). História na sala de aula: conceitos, práticas e propostas. São Paulo: Contexto, 2003.

SANTOS, Flávio Batista dos. O ensino da história local na formação da consciência his- 
tórica: um estudo com os alunos do Ensino Fundamental da cidade de Ibaiti-PR. 2014, 130f. Dissertação (Mestrado em Educação - orientação Prof.a Dr.a Marlene Cainelli). Universidade Estadual de Londrina. Paraná.

SCHMIDT, Maria Auxiliadora. O Ensino de História Local e os Desafios da Formação da Consciência Histórica. In: MONTEIRO, Ana Maria. GASPARELHO, Arlette Medeiros. MAGALHÃES, Marcelo de Souza (orgs.). Ensino de História: sujeitos, saberes e práticas. Rio de Janeiro. Mauad X: FAPERJ, 2007.

SCHMIDT, Maria Auxiliadora. GARCIA, Tânia Maria. A formação da consciência histórica de alunos e professores e o cotidiano em aulas de história. Cad. Cedes, Campinas, vol. 25, n. 67, p. 297-308, set./dez. 2005, p. 297-308. Disponível em http://www.cedes.unicamp.br acessado em 31.10.2016

SCHMIDT, Maria Auxiliadora. CAINELLI, Marlene. Ensinar História. São Paulo: Scipione, 2009. 2 ed.

SCHMIDT, Maria Auxiliadora. BARCA, Isabel. MARTINS, Estevão Rezende (orgs). Jörn Rüsen e o ensino de história. Curitiba: Editora UFPR, 2011.

SILVA, Isaíde Bandeira da. Ó, Glauceane Magalhães do. PIMENTEL, Luciana Maria Fernandes. História e Livro Didático. In: MAGALHÃES JUNIOR, Antônio Germano. ARAÚJO, Fátima Maria Leitão. Ensino \& linguagens da história (orgs.). Fortaleza: EdUECE, 2015.

SOARES, Marcelo André. RODRIGUES, Maria Emília Brito. Amapá: vivendo nossa história. Curitiba - PR: Base Editoria. 2008.

SOARES, Marcelo André. RODRIGUES, Maria Emília Brito. Amapá: vivendo nossa história. História Regional. Curitiba-PR: Base Editoria. 4으 e 5ㅇan ano do Ensino Fundamental. 2011.

ZAMBONI, Ernesta. Que História é essa? Uma proposta analítica dos livros paradidáticos de História. Tese (Doutorado em Educação, orientada pela Profa. Dra. Elza Nadai). Universidade Estadual de Campinas - São Paulo, 1991.

Artigo recebido em outubro de 2018 e aceito em novembro de 2018. 